\title{
First acute haemodynamic study of soluble guanylate cyclase stimulator riociguat in pulmonary hypertension
}

\author{
F. Grimminger*, G. Weimann\#, R. Frey*, R. Voswinckel*, M. Thamm*, \\ D. Bölkow*, N. Weissmann*, W. Mück\#, S. Unger", G. Wensing ${ }^{\#}$, \\ R.T. Schermuly* and H.A. Ghofrani*
}

ABSTRACT: Pulmonary hypertension (PH) is associated with impaired production of the vasodilator nitric oxide (NO). Riociguat (BAY 63-2521; Bayer Healthcare AG, Wuppertal, Germany) acts directly on soluble guanylate cyclase, stimulating the enzyme and increasing sensitivity to Iow NO levels. The present study evaluates riociguat safety, tolerability and efficacy in patients with moderate-to-severe $\mathrm{PH}$ (pulmonary arterial hypertension, distal chronic thromboembolic PH or PH with mild to moderate interstitial lung disease).

The optimal tolerated dose was identified by incremental dosing in four patients with $\mathrm{PH}$; pharmacodynamic and pharmacokinetic parameters were assessed following single-dose administration (2.5 $\mathrm{mg}$ or $1 \mathrm{mg}$ ) in 10 and five patients with $\mathrm{PH}$, respectively. All subjects $(n=19)$ were analysed for safety and tolerability.

Riociguat had a favourable safety profile at single doses $\leqslant 2.5 \mathrm{mg}$. It significantly improved pulmonary haemodynamic parameters and cardiac index in patients with $\mathrm{PH}$ in a dose-dependent manner, to a greater extent than inhaled NO. Although riociguat also had significant systemic effects and showed no pulmonary selectivity, mean systolic blood pressure remained $>110 \mathrm{mmHg}$.

The present report is the first to describe the use of riociguat in patients with pulmonary hypertension. The drug was well-tolerated and superior to nitric oxide in efficacy and duration. Riociguat, therefore, has potential as a novel therapy for pulmonary hypertension and warrants further investigation.

KEYWORDS: Maximum tolerated dose, pharmacokinetics, phase-Il clinical trial, pulmonary hypertension, soluble guanylyl cyclase, vasodilation

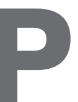
ulmonary arterial hypertension (PAH) defines a group of conditions characterised by increased pulmonary vascular resistance (PVR) leading to reduced right heart function and eventual heart failure [1]. It is a progressive disease with an extremely poor prognosis; if left untreated, median life expectancy following diagnosis is 2.8 yrs [2]. Although rare in the general population (15-52 cases per million) $[3,4]$, its prevalence increases in association with certain conditions. For example, PAH is diagnosed in $\sim 0.5 \%$ of patients infected with HIV $[5], 8-29 \%$ of patients with scleroderma $[6,7]$ and $11-32 \%$ of patients with sickle cell disease $[8,9]$.

$\mathrm{PAH}$ is caused by pulmonary vasoconstriction with vascular remodelling, formation of plexiform lesions and in situ thrombosis, which occur in response to aberrant production of a number of signalling factors. Expression of the vasoconstrictor endothelin is increased, while production of vasodilators such as prostacyclin and nitric oxide (NO) is decreased [10]. In healthy individuals, endothelial cell-derived $\mathrm{NO}$ acts on smooth muscle cells to induce vasodilation by increasing production of the second messenger cyclic guanosine monophosphate (cGMP) via activation of soluble guanylate cyclase (sGC) [11, 12].

Recent years have seen substantial progress in the treatment of $\mathrm{PAH}$, with the development of palliative therapies that target the $\mathrm{NO}$, endothelin and prostacyclin signalling pathways to promote vasodilation. However, although these
AFFILIATIONS

*Dept of Internal Medicine, University Hospital Giessen and Marburg, Giessen,

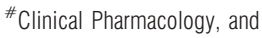
-Global Biostatistics, Bayer HealthCare AG, Pharma Research Centre, Wuppertal, Germany.

CORRESPONDENCE

H.A. Ghofrani

Dept of Internal Medicine,

Medical Clinic II/N

University Hospital Giessen and

Marburg GmbH

Klinikstrasse 36

35392 Giessen

Germany

Fax: 496419942419

E-mail: ardeschir.ghofrani@

innere.med.uni-giessen.de

Received:

March 142008

Accepted after revision:

November 212008

STATEMENT OF INTEREST

Statements of interest for $F$.

Grimminger, G. Weimann, R. Frey, N. Weissmann, W. Mück, S. Unger, G. Wensing, R.T. Schermuly and H.A. Ghofrani, and for the study itself, can be found at www.erj.ersjournals.com/ misc/statements.dtl 
developments have improved outcomes for patients with PAH, survival rates and quality of life remain relatively low [13].

Treatment of pulmonary hypertension $(\mathrm{PH})$ with NO-releasing agents such as nitrates has failed to produce beneficial long-term effects as, in most cases, negligible pulmonary vasodilatation was counterbalanced by significant peripheral reduction in vascular resistance and reflex tachycardia [14], which are poorly tolerated by patients with severe $\mathrm{PH}$. Inhaled NO is widely used as a short-term vasodilator to identify so-called responders to calcium channel blockers [15]. The long-term use of NO, however, is hampered by technical problems of administration, and life-threatening rebound $\mathrm{PH}$ can occur following interruption or discontinuation of $\mathrm{NO}$ inhalation [14]. An alternative therapeutic strategy targets downstream components of the NO signalling pathway by inhibiting phosphodiesterase-5, which regulates the conversion of the second messenger cGMP to GMP [16]. Sildenafil has been the lead substance in this group of agents, showing both acute and long-term beneficial effects in patients with PAH $[17,18]$. However, phosphodiesterase-5 inhibition is not effective in all patients with $\mathrm{PH}$ [19]. The full therapeutic potential of the NO signalling pathway, therefore, remains to be exploited.

Riociguat (BAY 63-2521; Bayer Healthcare AG, Wuppertal, Germany) offers a new mode of action for the treatment of PAH: in preclinical studies, it has been shown to stimulate sGC directly, increasing the enzyme's activity independently of
$\mathrm{NO}$, while also increasing sensitivity to low levels of NO. Treatment of two rodent models of $\mathrm{PH}$ with riociguat reduced pulmonary arterial pressure (PAP) and partially reversed cardiac hypertrophy and vascular remodelling [20]. The aim of the present clinical study was to evaluate the short-term safety profile, tolerability and efficacy of riociguat in patients with moderate to severe $\mathrm{PH}$.

\section{METHODS}

\section{Patients}

Male and female patients aged 18-80 yrs were eligible for inclusion if they had a mean PVR $>300 \mathrm{dyn} \cdot \mathrm{s} \cdot \mathrm{cm}^{-5}$ and a diagnosis of $\mathrm{PAH}$, distal chronic thromboembolic $\mathrm{PH}$ or $\mathrm{PH}$ associated with mild to moderate interstitial lung disease. Catheters for haemodynamic measurements were placed on clinical grounds independently of the trial. A 12-h washout period was observed for acute vasodilatory substances such as calcium channel blockers and phosphodiesterase- 5 inhibitors.

Patients were excluded from the study if they had any of the following: pre-existing lung diseases (other than interstitial lung disease as defined in the protocol), significant left heart dysfunction, significantly impaired gas exchange (partial pressure of carbon dioxide in arterial blood $\left(\mathrm{Pa}_{1} \mathrm{CO}_{2}\right)$ $>55 \mathrm{mmHg}(>7.3 \mathrm{kPa}))$, deficiencies of blood coagulation or evidence of latent bleeding risk, sickle cell anaemia, peripheral organ dysfunction or immunodeficiencies. Females with childbearing potential were excluded if they were not using a

a)

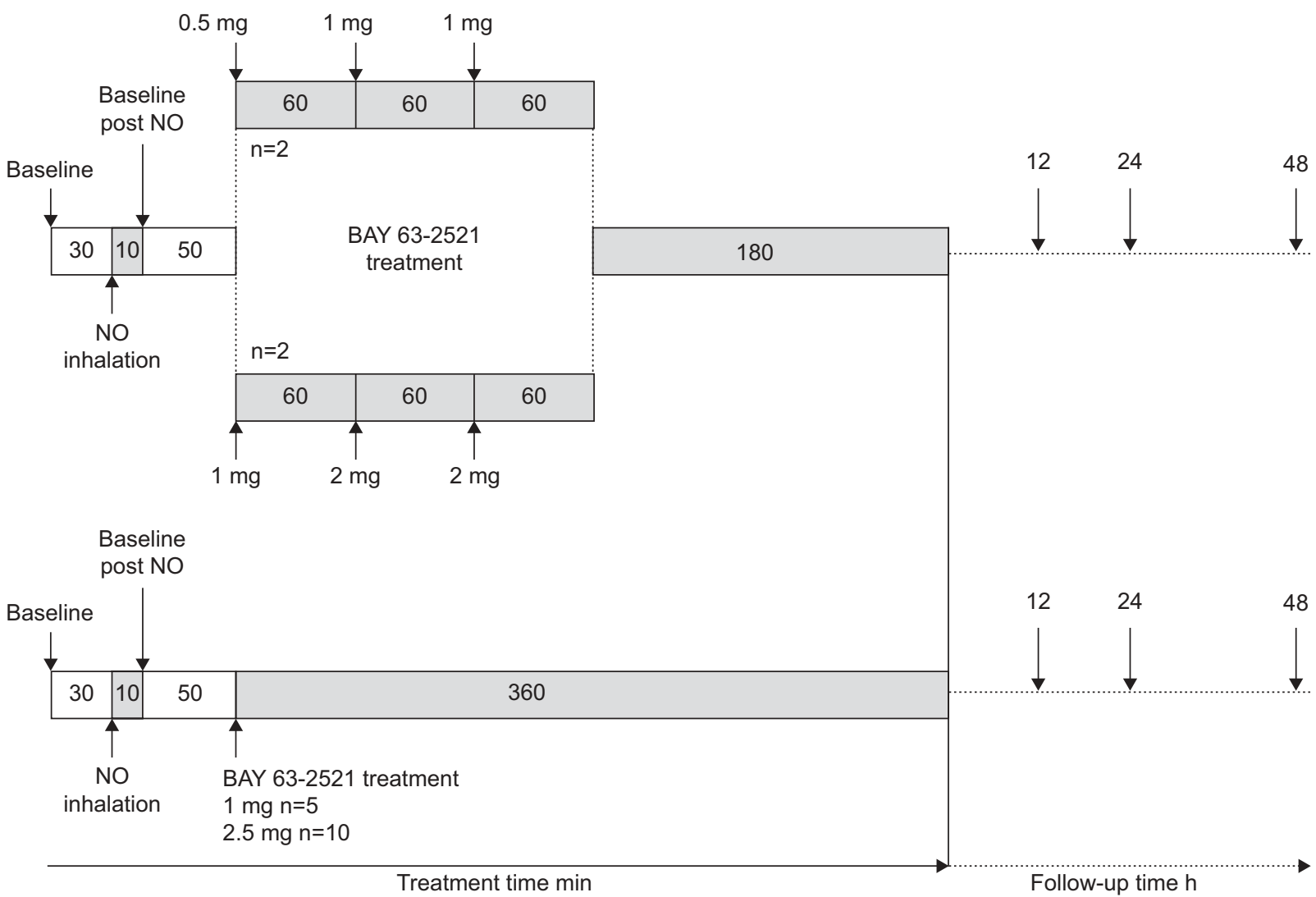

FIGURE 1. Treatment schedules for evaluation of riociguat (BAY 63-2521) in patients with pulmonary hypertension. a) Identification of maximum tolerated dose. b) Evaluation of $1 \mathrm{mg}$ and $2.5 \mathrm{mg}$ doses. NO: nitric oxide. 
TABLE 1 Treatment-emergent adverse events and possible relationship to study drug

\begin{tabular}{|c|c|c|c|c|c|}
\hline & \multirow[t]{2}{*}{ iNO } & \multicolumn{4}{|c|}{ Riociguat } \\
\hline & & \multicolumn{2}{|c|}{ Incremental dose } & \multicolumn{2}{|c|}{ Single dose } \\
\hline Subjects $\mathbf{n}$ & 19 & 2 & 2 & 5 & 10 \\
\hline Adverse events ${ }^{\#}$ & $0(0)$ & $1(50)$ & $1(50)$ & $1(20)$ & $1(10)$ \\
\hline Vascular disorders & & Hot flush $^{+}$ & & & \\
\hline Nervous system disorders & & & & Dizziness $^{+}$ & \\
\hline Respiratory, thoracic and mediastinal disorders & & & & Cough" & Nasal congestion ${ }^{+}$ \\
\hline
\end{tabular}

reliable contraceptive measure. Patients were also excluded if they had participated in another study during the 30 days preceding the current study, or if they had undergone previous therapeutic radiation of lung or mediastinum. During the trial, use of medication other than the investigational product was permitted only after consultation with the investigator, and all concomitant medications were documented.

\section{Study design}

Riociguat was administered in the morning after a fasting period of $\geqslant 8 \mathrm{~h}$. After a first baseline evaluation lasting $30 \mathrm{~min}$, every patient underwent a NO inhalation period of $10 \mathrm{~min}(10$ 20 ppm NO required for maximum vasodilatation), followed by a second baseline period of $50 \mathrm{~min}$. Haemodynamic and gas exchange variables were measured twice during the NO inhalation period and the second baseline period. BAY 63-2521 was administered orally in solution (unit of dosage: $0.5 \mathrm{mg} \cdot \mathrm{mL}^{-1}$ ) after haemodynamic variables returned to baseline values.

In part A of the study, which was designed to identify the dose of riociguat that has maximal clinical effect without compromising

\begin{tabular}{|c|c|c|}
\hline $\begin{array}{l}\text { TABLE } 2 \text { Baseline } \\
\text { study par }\end{array}$ & \multicolumn{2}{|c|}{$\begin{array}{l}\text { Baseline pharmacodynamic characteristics in } \\
\text { study part B }\end{array}$} \\
\hline \multirow[t]{2}{*}{ Parameter } & \multicolumn{2}{|c|}{ Riociguat } \\
\hline & $1 \mathrm{mg}$ & $2.5 \mathrm{mg}$ \\
\hline Subjects $\mathrm{n}$ & 5 & 10 \\
\hline mPAP $\mathrm{mmHg}$ & $55.4 \pm 16.6$ & $42.1 \pm 11.3$ \\
\hline PVR dyn $\cdot s \cdot \mathrm{cm}^{-5}$ & $1028 \pm 491$ & $566 \pm 209$ \\
\hline SBP $\mathrm{mmHg}$ & $147 \pm 25$ & $133 \pm 20$ \\
\hline SVR dyn $\cdot s \cdot \mathrm{cm}^{-5}$ & $2127 \pm 407$ & $1324 \pm 335$ \\
\hline Cardiac index $\mathrm{L} \cdot \mathrm{min}^{-1} \cdot \mathrm{m}^{-2}$ & $2.17 \pm 0.18$ & $2.74 \pm 0.82$ \\
\hline Heart rate beats $\cdot \mathrm{min}^{-1}$ & $84 \pm 12$ & $73 \pm 10$ \\
\hline
\end{tabular}

safety and tolerability, four patients were given hourly incremental doses $(0.5+1+1 \mathrm{mg}=2.5 \mathrm{mg}(\mathrm{n}=2)$ and $1+2+2 \mathrm{mg}=5 \mathrm{mg}$ $(n=2))$. Dose titration was terminated if the mean arterial pressure fell to $<60 \mathrm{mmHg}$ or if the heart rate exceeded 140 beats $\cdot \mathrm{min}^{-1}$ (fig. 1a). In part B, $1 \mathrm{mg}$ and $2.5 \mathrm{mg}$ single doses of riociguat were evaluated in five and 10 patients, respectively (fig. 1b). Measurements obtained for riociguat treatment were compared with peak intervention values for inhaled NO and post-NO intervention baseline values.

The study protocol and any substantial amendments were approved by the Bundesinstitut für Arzneimittel und Medizinprodukte (BfArM; Bonn, Germany) and the Ethics Committee of the University of Giessen Medical Faculty (Giessen, Germany). Each patient gave written informed consent.

\section{Safety and tolerability}

Safety and tolerability were evaluated using standard vital sign and laboratory biochemistry. The subjective tolerability of riociguat was evaluated by questioning the subjects about adverse events or by spontaneous reporting of adverse events. Clinical adverse events were classified according to their degree of severity (mild, moderate or severe), and it was also noted whether or not they were serious. Patients were assessed for $48 \mathrm{~h}$ following administration of riociguat.

\section{Pharmacodynamics}

The pharmacodynamic effects of the drug were assessed using Swan-Ganz catheterisation, blood gas measurements and multiple inert gas elimination technique (MIGET) as described previously [21].

Swan-Ganz haemodynamic measurements included direct measurements, such as mean right atrial pressure (mRAP; $\mathrm{mmHg}$ ), pulmonary arterial pressures (systolic PAP, diastolic PAP and mean PAP (mPAP; mmHg)), pulmonary capillary wedge pressure (PCWP; $\mathrm{mmHg}$ ), heart rate (beats $\cdot \mathrm{min}^{-1}$ ), systemic blood pressure (systolic (SBP), diastolic and arterial mean $(\mathrm{mSAP}) ; \mathrm{mmHg})$, cardiac output $\left(\mathrm{CO} ; \mathrm{L} \cdot \mathrm{min}^{-1}\right.$ (average of three measurements, performed and calculated by $\mathrm{CO}$ thermodilution device)), body weight $(\mathrm{kg})$ and height $(\mathrm{cm})$. 

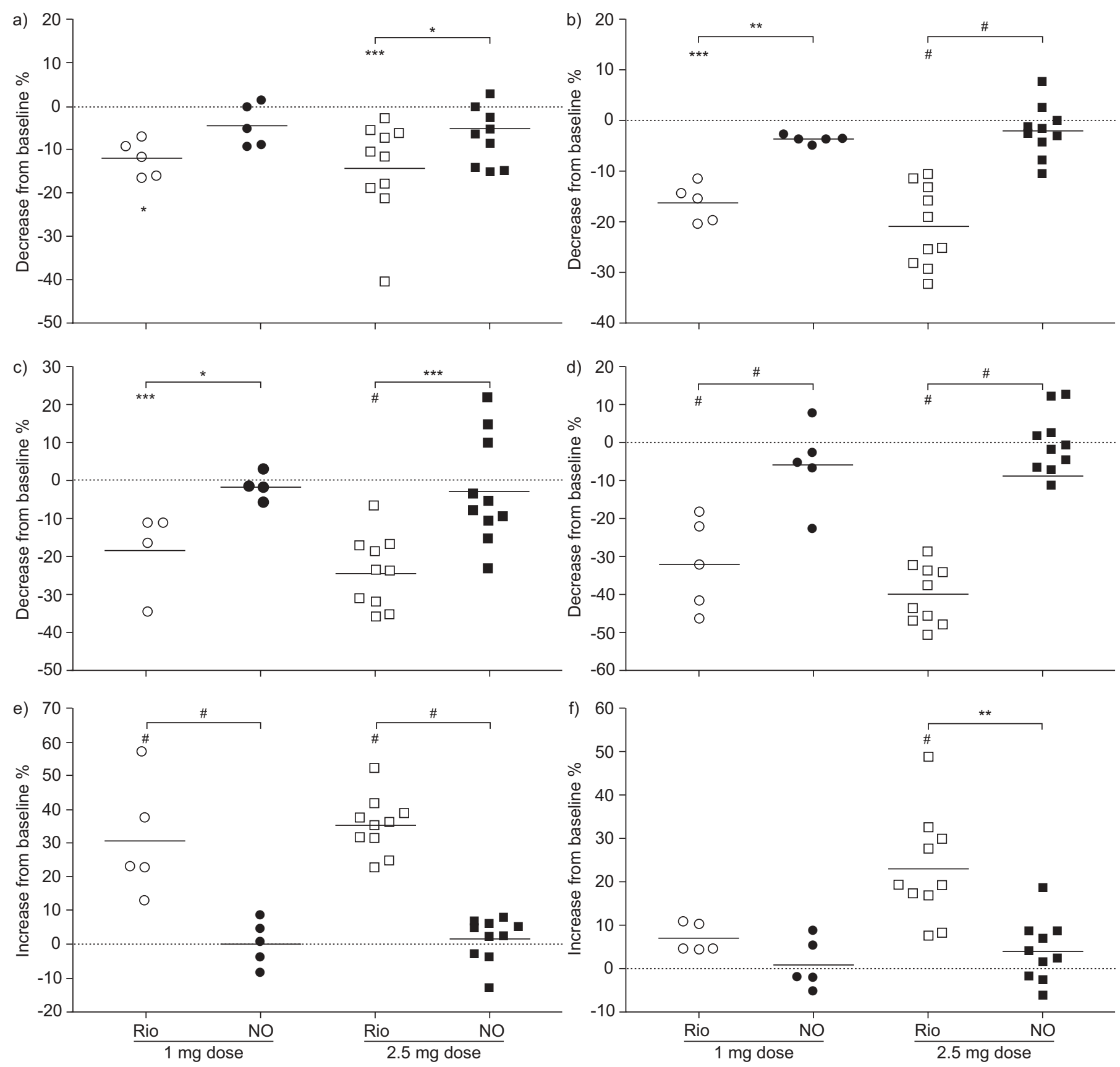

FIGURE 2. Changes in haemodynamic parameters following a single dose of riociguat (Rio) compared with inhaled nitric oxide (NO). Percentage decrease from baseline of a) mean pulmonary arterial pressure, b) systolic blood pressure, c) pulmonary vascular resistance and d) systemic vascular resistance. Percentage increase from baseline of e) cardiac index and f) heart rate. Horizontal lines indicate point estimates (least-squares means) in each case. Statistical significance was measured by the $F$ statistic. ${ }^{*}: p<0.05 ;{ }^{* *}: p<0.01 ; * * *: p<0.001 ;{ }^{*}: p<0.0001$.

Calculated measurements included body surface area (BSA; equation 1, Dubois formula), PVR (equation 2), systemic vascular resistance (SVR; equation 3) and cardiac index (equation 4).

BSA (in $\mathrm{m}^{2}$ )=weight $(\text { in } \mathrm{kg})^{0.425} \times$ height $(\text { in } \mathrm{cm})^{0.725}$

$$
\times 0.007184
$$

PVR (in dyn $\left.\cdot \mathrm{s} \cdot \mathrm{cm}^{-5}\right)=80 \times(\mathrm{PAP}-\mathrm{PCWP}) / \mathrm{CO}$

SVR $\left(\right.$ in dyn $\left.\cdot s \cdot \mathrm{cm}^{-5}\right)=80 \times(\mathrm{mSAP}-\mathrm{mRAP}) / \mathrm{CO}$

$$
\text { cardiac index }\left(\text { in } \mathrm{L} \cdot \mathrm{min}^{-1} \cdot \mathrm{m}^{-2}\right)=\mathrm{CO} / \mathrm{BSA}
$$

Blood gas analysis measurements included arterial oxygen tension $\left(\mathrm{Pa}_{1} \mathrm{O}_{2} ; \mathrm{mmHg}\right), \quad \mathrm{Pa}_{1} \mathrm{CO}_{2}(\mathrm{mmHg})$, arterial oxygen saturation $(\%)$, mixed venous oxygen tension $(\mathrm{mmHg})$ and venous oxygen saturation (\%).

MIGET measured total ventilation $\left(\mathrm{L} \cdot \mathrm{min}^{-1}\right)$, total perfusion $\left(\mathrm{L} \cdot \mathrm{min}^{-1}\right)$, deadspace ventilation (per cent of total ventilation), (3) low ventilation/perfusion $\left(V^{\prime} / Q^{\prime}\right)$ perfusion $\left(V^{\prime} / Q^{\prime} 0.001-0.1 \%\right.$ 
of total perfusion), normal $V^{\prime} / Q^{\prime}$ perfusion $\left(V^{\prime} / Q^{\prime} 0.1-10 \%\right.$ of total perfusion), ventilation-perfusion distribution (standard deviation of perfusion and standard deviation of ventilation) and intrapulmonary shunt flow (per cent of total perfusion).

In order to assess the relationship between riociguat plasma concentration and the effect on PAP, SBP, PVR, SVR and cardiac index (measured as the ratio to baseline), Spearman's rank correlation coefficients along with 95\% confidence intervals were calculated for each parameter and all subjects.

\section{Pharmacokinetics}

Riociguat plasma concentrations were determined by HPLC-MS assay, using blood samples obtained at regular intervals up to $48 \mathrm{~h}$ after riociguat administration. Primary parameters included the following: area under the plasma concentration versus time curve from zero to infinity (AUC); AUC divided by dose (mg), expressed per $\mathrm{kg}$ body weight $\left(\mathrm{AUC}_{\mathrm{norm}}\right)$; maximum drug concentration in plasma after single dose administration $\left(C_{\max }\right)$; and $\mathrm{C}_{\max }$ divided by dose $(\mathrm{mg})$, expressed per $\mathrm{kg}$ body weight $\left(C_{\text {max,norm }}\right)$. Secondary parameters included time to reach maximum drug concentration in plasma, and half-life associated with terminal elimination. Apparent volume of distribution during terminal phase after oral administration and total body clearance of drug from plasma after oral administration were also calculated.

The influence of riociguat dose on pharmacokinetic parameters was assessed by performing an explorative ANOVA (including factor "dose") on the log-transformed values of $\mathrm{AUC}_{\text {norm }}$ and $\mathrm{C}_{\text {max,norm }}$ in the single-dose study.

\section{RESULTS}

\section{Patient demographics}

Patient demographics are summarised in the online supplementary material. There was no clinically relevant difference in

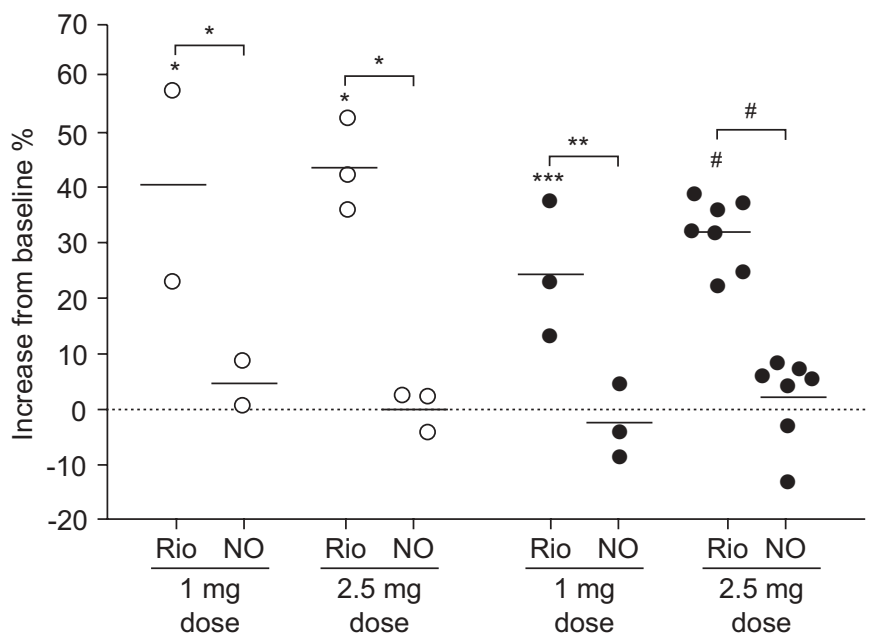

FIGURE 3. Change from baseline of cardiac index in patients with distal chronic thromboembolic pulmonary hypertension $(\bigcirc)$ or pulmonary arterial hypertension (-) following a single dose of riociguat (Rio) compared with inhaled nitric oxide (NO). Horizontal lines indicate point estimates (least-squares means) in each case. Statistical significance was measured by the $F$ statistic. *: $p<0.05$; $* *: p<0.01 ;{ }^{* *}: p<0.001 ;{ }^{*}: p<0.0001$. No significant differences in response to drug were observed between the two disease entities. patient demographics between study part $\mathrm{A}$ and part $\mathrm{B}$ Patients enrolled in part B showed no statistically significant differences in age, height, weight or body mass index between dose groups. The $1 \mathrm{mg}$ dose group had a higher proportion of females than the $2.5 \mathrm{mg}$ dose group. Medications used by patients prior to the study are presented in the online supplementary material.

\section{Safety and tolerability}

No serious adverse events occurred in the study (table 1). Overall, six mild adverse events were documented in four out of 19 patients, all of which had resolved by study completion. Three adverse events were considered to be drug-related and attributable to the pharmacological properties of the test compound.

Riociguat at a dose of $\leqslant 2.5 \mathrm{mg}$ had no clinically relevant effects on vital signs, electrocardiograms or laboratory values, and no major changes were noted in blood gases $\left(\mathrm{Pa}_{2} \mathrm{O}_{2}, \mathrm{~Pa}_{\mathrm{a}} \mathrm{CO}_{2}\right.$ blood oxygen saturation) or $V^{\prime} / Q^{\prime}$ matching. Riociguat was well tolerated up to $2.5 \mathrm{mg}$, whereas a total dose of $5 \mathrm{mg}$ in study part A caused asymptomatic hypotension in one patient. Therefore, a $2.5 \mathrm{mg}$ dose was used in part B to demonstrate efficacy; $1 \mathrm{mg}$ was chosen to test for the first effect level.

\section{Pharmacodynamics}

Baseline pharmacodynamic parameters are shown in table 2 . Inhaled NO led to small, nonsignificant reductions from baseline in mPAP, SBP, PVR and SVR, and no relevant changes were observed for cardiac index or heart rate (fig. 2). mPAP, SBP, PVR and SVR showed a similar maximum decrease in response to $\mathrm{NO}$ inhalation in both $1 \mathrm{mg}$ and $2.5 \mathrm{mg}$ dose groups.

Both 1 and $2.5 \mathrm{mg}$ doses of riociguat caused clinically relevant and statistically significant reductions from baseline in $\mathrm{MPAP}$, PVR, SBP and SVR to a similar extent. A clinically relevant and statistically significant increase in cardiac index was also observed with both doses ( $p$-value between 0.0151 and $<0.0001$; fig. 2), whereas a significant increase in heart rate was only observed in the $2.5 \mathrm{mg}$ dose group. Both doses of riociguat were superior to NO in reducing PVR, SBP and SVR and increasing cardiac index (p-value between 0.0220 and $<0.0001$; fig. 2), and the $2.5 \mathrm{mg}$ dose was superior to $\mathrm{NO}$ in reducing $\mathrm{mPAP}(\mathrm{p}=0.0341$; fig. $2 \mathrm{a})$. Riociguat had a similar effect in patient subgroups with $\mathrm{PAH}$ or chronic thromboembolic $\mathrm{PH}$, significantly increasing cardiac index to a greater extent than NO (fig. 3). Riociguat plasma concentrations correlated significantly with the reductions in $\mathrm{mPAP}, \mathrm{SBP}$, PVR and SVR, and the concomitant increase in cardiac index (table 3; fig. 4a). Neither dose of riociguat produced any deterioration in gas exchange or $V^{\prime} / Q^{\prime}$ matching (as measured by MIGET), despite causing strong pulmonary vasodilation (see online supplementary material).

\section{Pharmacokinetics}

Following single-dose administration of riociguat solution, plasma concentrations of riociguat showed dose-dependent increases with pronounced interindividual variability (fig. 4b). Peak concentrations of riociguat were reached after $0.25-1.5 \mathrm{~h}$, and its half-life was 10-12 h (table 4). $C_{\max }$ and AUC values for riociguat suggested dose proportionality for the 1 and $2.5 \mathrm{mg}$ 


\begin{tabular}{|c|c|c|c|}
\hline TABLE 3 & $\begin{array}{l}\text { Statistics o } \\
\text { riociguat d } \\
\text { arterial pre } \\
\text { (SBP), puln } \\
\text { systemic v } \\
\text { index }\end{array}$ & $\begin{array}{l}\text { n Spearman correlatio } \\
\text { rug concentration and } \\
\text { ssure (PAP), systolic b } \\
\text { nonary vascular resista } \\
\text { ascular resistance (SV }\end{array}$ & $\begin{array}{l}\text { petween } \\
\text { pulmonary } \\
\text { lood pressure } \\
\text { ance (PVR), } \\
\text { R) and cardiac }\end{array}$ \\
\hline Parameter & Unit & Correlation $(95 \% \mathrm{Cl})$ & Two-sided $p>|z|$ \\
\hline PAP & $\mathrm{mmHg}$ & $-0.2550(-0.3827--0.1274)$ & $<0.0001$ \\
\hline SBP & $\mathrm{mmHg}$ & $-0.5569(-0.6531--0.4607)$ & $<0.0001$ \\
\hline PVR & dyn $\cdot s \cdot \mathrm{cm}^{-5}$ & $-0.4733(-0.5815--0.3650)$ & $<0.0001$ \\
\hline SVR & dyn $\cdot s \cdot \mathrm{cm}^{-5}$ & $-0.5910(-0.6879--0.4942)$ & $<0.0001$ \\
\hline Cardiac index & $\mathrm{L} \cdot \mathrm{min}^{-1} \cdot \mathrm{m}^{-2}$ & $0.4543(0.3411-0.5674)$ & $<0.0001$ \\
\hline
\end{tabular}

doses (table 4); this was supported by ANOVA results, which showed that factor dose had no influence on either parameter

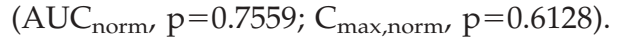

\section{DISCUSSION}

In the present proof-of-concept study in patients with $\mathrm{PAH}$, distal chronic thromboembolic $\mathrm{PH}$ or $\mathrm{PH}$ associated with mild to moderate interstitial lung disease (mean PVR $>300 \mathrm{dyn} \cdot \mathrm{s} \cdot \mathrm{cm}^{-5}$ ), doses of 1 or $2.5 \mathrm{mg}$ of riociguat significantly reduced PVR and also improved PAP and cardiac index in a concentration-dependent manner. Both doses demonstrated greater potency and duration of action than inhaled NO, which had a small, statistically insignificant effect in the study, consistent with the fact that a substantial proportion of $\mathrm{PH}$ patients does not respond to NO inhalation [22]. Neither dose of riociguat produced any deterioration in gas exchange or $V^{\prime} / Q^{\prime}$ matching, despite strong pulmonary vasodilation.

Riociguat had a favourable safety profile, with a single dose of $2.5 \mathrm{mg}$ being well tolerated. A total dose of $5 \mathrm{mg}$ administered in hourly increments gave rise to asymptomatic hypotension in one patient in part A; therefore, subsequent tests were limited to a maximum dose of $2.5 \mathrm{mg}$. The favourable safety profile observed in the present study is in agreement with a previous phase-I study, in which riociguat at oral doses of up to $5.0 \mathrm{mg}$ was well tolerated by healthy male volunteers [23].

Oral riociguat was effective in the current study, thus offering the patient a simple and convenient mode of administration. Oral therapies currently approved for the treatment of $\mathrm{PAH}$ comprise endothelin receptor agonists (ERAs) and phosphodiesterase-5 inhibitors. Although these therapies have helped to improve the prognosis for patients with $\mathrm{PAH}$, survival rates remain relatively poor [13], suggesting that a new approach is required. In addition, ERAs are associated with an increased risk of hepatotoxicity [24]. Riociguat did not demonstrate any hepatotoxicity in the current short-term study, supporting previous work in experimental models and human volunteer studies [23]: no significant abnormalities in laboratory values were recorded in association with the trial, apart from one case of slightly elevated glutamate dehydrogenase, pre-existent in a patient who had been treated with
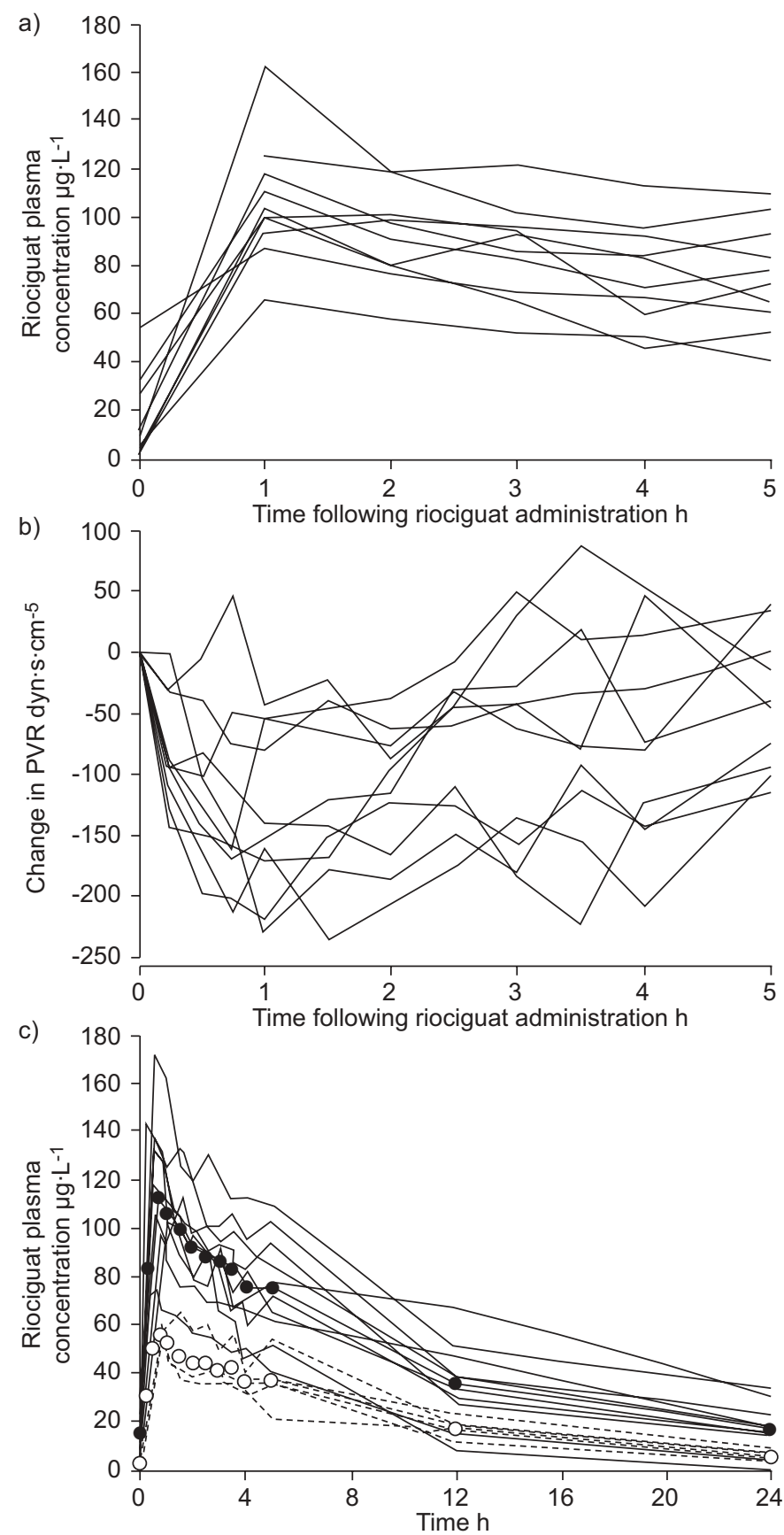

FIGURE 4. Pharmacokinetic analysis of riociguat following a single oral dose. Comparison of a) riociguat plasma concentration with b) changes in pulmonary vascular resistance (PVR) from baseline over time. c) Study part B: riociguat plasma concentrations following a single oral dose of $1 \mathrm{mg}$ and $2.5 \mathrm{mg}$ riociguat solution. Data are shown for each individual patient, and geometric means for the $2.5 \mathrm{mg}$ (-) and $1 \mathrm{mg}(\bigcirc)$ dose groups are also indicated. Subjects valid for pharmacokinetic analysis; $n=15$.

ERAs before the study and who had a history of intermittent increases of liver enzymes.

The phosphodiesterase- 5 inhibitor sildenafil is widely used and well-tolerated as a therapy for $\mathrm{PAH}$, and has demonstrated a degree of pulmonary selectivity despite being administered orally [25], presumably due to the relatively 


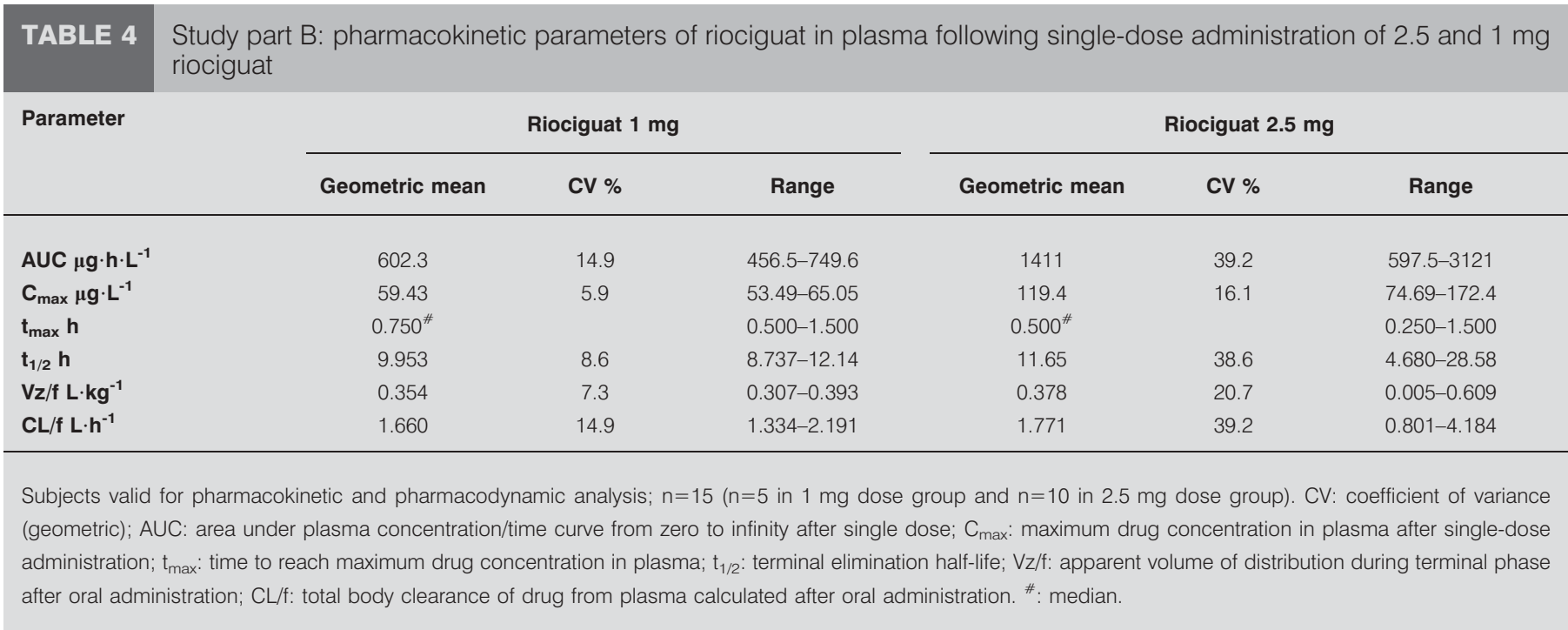

high expression of phosphodiesterase-5 in the lung [26]. However, its efficacy is dependent on the presence of an intact NO-sGC-cGMP axis [27], and may be limited in the presence of low levels of NO; sildenafil blocks degradation of cGMP and, thus, depends on the presence of NO stimulating sGC, in contrast to riociguat which can increase cGMP synthesis in the absence of NO. Although various doses of sildenafil (20-80 mg t.i.d.) were used in the SUPER-1 (sildenafil use in pulmonary arterial hypertension) trial [18], and the bulk of long-term experience with this drug is with doses of $>20 \mathrm{mg}$ t.i.d., agencies have only approved the lowest dose of $20 \mathrm{mg}$ t.i.d. for long-term treatment, which could be too low for some patients [16]. The synergistic action of riociguat with low levels of NO may provide a means to increase cGMP levels and, thus, promote vasodilation in combination with sildenafil or in patients who do not respond to sildenafil, while also ensuring maintenance of $V^{\prime} / Q^{\prime}$ matching.

Riociguat significantly reduced SBP and SVR in the current study and, therefore, did not demonstrate pulmonary selectivity although, interestingly, the systemic vasodilation was not accompanied by any relevant side-effects (table 1). This may have been due to a compensatory increase in $\mathrm{CO}$. Although the observed systemic effects of riociguat were asymptomatic in the present short-term study of supine patients, its long-term effect on mobile patients may be more significant and must be examined in future studies.

The current study has certain limitations, for example the small and heterogeneous patient population exposed to the drug, lack of a placebo group and the observation of short-term effects only. In addition, plasma cGMP levels, which would have provided information regarding the direct effect of riociguat on sGC activity, were not assessed. Nevertheless, the results of the study present riociguat as a promising novel therapeutic principle that warrants further investigation.

Direct NO-independent stimulation of sGC and sensitisation of sGC to low levels of endogenous NO may offer distinct advantages over current therapeutic approaches and opens access to a completely new class of drugs for cardiovascular indications [28]. Riociguat stimulates the NO target sGC directly to create a strong vasodilatory effect irrespective of integrity of endothelial function and NO production, and also acts synergistically in the presence of $\mathrm{NO}$, offering a new mode of action for the treatment of $\mathrm{PH}$. In the present study, convenient oral doses of riociguat demonstrated efficacy, tolerability and durable action, with no deterioration in gas exchange. Comparison of this promising drug with established therapies, such as sildenafil, and assessment of its efficacy as an add-on therapy or in patients who do not respond to existing treatments, would be of great interest in future studies.

In conclusion, the present study demonstrates the efficacy of riociguat in lowering pulmonary vascular resistance and improving cardiac function in patients with moderate-tosevere pulmonary hypertension. Therefore, as a representative of a new class of drugs hitherto not evaluated in cardiovascular disease, riociguat offers great therapeutic potential as a treatment for patients with pulmonary vascular disorders. The encouraging results of the current acute haemodynamic study warrant further long-term controlled clinical trials in this field. A multicentre phase-II trial has recently been initiated to address this issue.

\section{ACKNOWLEDGEMENTS}

Parts of the doctoral thesis of D. Bölkow are incorporated in this report. C. Mulligan from Oxford PharmaGenesis(IM provided editorial assistance funded by Bayer HealthCare AG.

\section{REFERENCES}

1 Gaine SP, Rubin LJ. Primary pulmonary hypertension. Lancet 1998; 352: 719-725.

2 D'Alonzo GE, Barst RJ, Ayres SM, et al. Survival in patients with primary pulmonary hypertension. Results from a national prospective registry. Ann Intern Med 1991; 115: 343-349.

3 Humbert M, Sitbon O, Chaouat A, et al. Pulmonary arterial hypertension in France: results from a national registry. Am J Respir Crit Care Med 2006; 173: 1023-1030. 
4 Peacock AJ, Murphy NF, McMurray JJ, Caballero L, Stewart S. An epidemiological study of pulmonary arterial hypertension. Eur Respir J 2007; 30: 104-109.

5 Speich R, Jenni R, Opravil M, Pfab M, Russi EW. Primary pulmonary hypertension in HIV infection. Chest 1991; 100: 1268-1271.

6 Hachulla E, Gressin V, Guillevin L, et al. Early detection of pulmonary arterial hypertension in systemic sclerosis: a French nationwide prospective multicenter study. Arthritis Rheum 2005; 52: 3792-3800.

7 Plastiras SC, Karadimitrakis SP, Kampolis C, Moutsopoulos HM, Tzelepis GE. Determinants of pulmonary arterial hypertension in scleroderma. Semin Arthritis Rheum 2007; 36: 392-396.

8 Billy-Brissac R, Blanchet-Deverly A, Etienne-Julan M, Foucan L. Pulmonary hypertension in an adult sickle cell population in Guadeloupe. Int J Cardiol 2008; [Epub ahead of print PMID: 18466988].

9 Gladwin MT, Sachdev V, Jison ML, et al. Pulmonary hypertension as a risk factor for death in patients with sickle cell disease. N Engl J Med 2004; 350: 886-895.

10 McLaughlin VV, McGoon MD. Pulmonary arterial hypertension. Circulation 2006; 114: 1417-1431.

11 Ignarro LJ, Buga GM, Wood KS, Byrns RE, Chaudhuri G. Endothelium-derived relaxing factor produced and released from artery and vein is nitric oxide. Proc Natl Acad Sci USA 1987; 84: 9265-9269.

12 Arnold WP, Mittal CK, Katsuki S, Murad F. Nitric oxide activates guanylate cyclase and increases guanosine $3^{\prime}: 5^{\prime}-$ cyclic monophosphate levels in various tissue preparations. Proc Natl Acad Sci USA 1977; 74: 3203-3207.

13 Naeije R, Huez S. Expert opinion on available options treating pulmonary arterial hypertension. Expert Opin Pharmacother 2007; 8: 2247-2265.

14 Atz AM, Adatia I, Wessel DL. Rebound pulmonary hypertension after inhalation of nitric oxide. Ann Thorac Surg 1996; 62: 1759-1764.

15 Sitbon O, Brenot F, Denjean A, et al. Inhaled nitric oxide as a screening vasodilator agent in primary pulmonary hypertension. A dose-response study and comparison with prostacyclin. Am J Respir Crit Care Med 1995; 151: 384-389.

16 Ghofrani HA, Osterloh IH, Grimminger F. Sildenafil: from angina to erectile dysfunction to pulmonary hypertension and beyond. Nat Rev Drug Discov 2006; 5: 689-702.
17 Ghofrani HA, Wiedemann R, Rose F, et al. Combination therapy with oral sildenafil and inhaled iloprost for severe pulmonary hypertension. Ann Intern Med 2002; 136: 515-522.

18 Galie N, Ghofrani HA, Torbicki A, et al. Sildenafil citrate therapy for pulmonary arterial hypertension. $N$ Engl J Med 2005; 353: 2148-2157.

19 Bhatia S, Frantz RP, Severson CJ, Durst LA, McGoon MD. Immediate and long-term hemodynamic and clinical effects of sildenafil in patients with pulmonary arterial hypertension receiving vasodilator therapy. Mayo Clin Proc 2003; 78: 1207-1213.

20 Schermuly R, Stasch JP, Pullamsetti SS, et al. Expression and function of soluble guanylate cyclase in pulmonary arterial hypertension. Eur Respir J 2008; 32: 881-891.

21 Ghofrani HA, Wiedemann R, Rose F, et al. Sildenafil for treatment of lung fibrosis and pulmonary hypertension: a randomised controlled trial. Lancet 2002; 360: 895-900.

22 Klinger JR, Thaker S, Houtchens J, Preston IR, Hill NS, Farber HW. Pulmonary hemodynamic responses to brain natriuretic peptide and sildenafil in patients with pulmonary arterial hypertension. Chest 2006; 129: 417-425.

23 Frey R, Mück W, Unger S, Artmeier-Brandt U, Weimann G, Wensing G. Single-dose pharmacokinetics, tolerability and safety of the soluble guanylate cyclase stimulator BAY 632521; an ascending-dose study in healthy male volunteers. J Clin Pharmacol 2008; 48: 926-934.

24 Humbert M, Segal ES, Kiely DG, Carlsen J, Schwierin B, Hoeper MM. Results of European post-marketing surveillance of bosentan in pulmonary hypertension. Eur Respir J 2007; 30: 338-344.

25 Ghofrani HA, Voswinckel R, Reichenberger F, et al. Differences in hemodynamic and oxygenation responses to three different phosphodiesterase- 5 inhibitors in patients with pulmonary arterial hypertension: a randomized prospective study. J Am Coll Cardiol 2004; 44: 1488-1496.

26 Corbin JD, Beasley A, Blount MA, Francis SH. High lung PDE5: a strong basis for treating pulmonary hypertension with PDE5 inhibitors. Biochem Biophys Res Commun 2005; 334: 930-938.

27 Michelakis ED. The role of the NO axis and its therapeutic implications in pulmonary arterial hypertension. Heart Fail Rev 2003; 8: 5-21.

28 Evgenov OV, Pacher P, Schmidt PM, Hasko G, Schmidt HH, Stasch JP. NO-independent stimulators and activators of soluble guanylate cyclase: discovery and therapeutic potential. Nat Rev Drug Discov 2006; 5: 755-768. 